\title{
Genetic relationships of Pacific abalone (Haliotidae) species determined using universal rice primer-polymerase chain reaction fingerprinting
}

\author{
H.S. An, J.Y. Park, J.I. Myeong and C.M. An \\ Biotechnology Research Division, \\ National Fisheries Research and Development Institute, Busan, Korea \\ Corresponding author: H.S. An \\ E-mail: hsan97@korea.kr
}

Genet. Mol. Res. 12 (4): 6309-6318 (2013)

Received May 21, 2013

Accepted September 12, 2013

Published December 4, 2013

DOI http://dx.doi.org/10.4238/2013.December.4.18

\begin{abstract}
Random amplified polymorphic DNA (RAPD) with universal rice primers (URP) was used to identify species and to determine phylogenetic relationships for the 6 economically important Korean Pacific abalone species: Haliotis discus hannai, H. discus discus, $H$. madaka, $H$. gigantea, $H$. diversicolor supertexta, and $H$. diversicolor diversicolor, whose morphological differentiation is difficult. Of the 12 URPs used in this study, 7 were effective in producing reproducible RAPD markers for these 6 species. Amplifications with the 7 URP primers yielded 129 reproducible amplified fragments ranging between 100 and $6000 \mathrm{bp}$ in length. The dendrogram generated by the unweighted pairgroup method using arithmetic averages showed that the 6 species were divided into 4 groups at 0.44 similarity level, indicating that they were genetically distant from each other and had little internal phylogenetic resolution. One group included $H$. discus hannai, $H$. discus discus, $H$. madaka, and $H$. gigantea, which were divided into 2 groups at 0.52 similarity level: one group of $H$. discus hannai, $H$. discus discus, and $H$.
\end{abstract}


madaka, and the other of $H$. gigantea. $H$. diversicolor supertexta and $H$. diversicolor diversicolor belonged to the other group. Furthermore, the reproducible pattern of amplified DNA bands by URP primers indicated the possibility of using these as molecular markers for the discrimination of the 6 Pacific abalone species. These results suggest that the URPPCR approach will be a useful tool for obtaining accurate taxonomic identification and genetic relationship of Korean Pacific abalones, which is one of the first prerequisites in effective conservation programs.

Key words: URP primer; Genetic relationship; Korean Pacific abalone; Random amplified polymorphic DNA (RAPD); Molecular marker

\section{INTRODUCTION}

Abalones are gastropod mollusks belonging to the genus Haliotis (Mollusca: Gastropoda). Pacific abalones are economically important mollusk species in Eastern Asia: the meat of this mollusk is considered a delicacy and the availability of commercially farmed abalone has allowed more common consumption of this once rare delicacy (Zhang et al., 1998). In Korea, 6 species of abalone have been reported to occur along the coasts: $H$. discus hannai Ino, $H$. discus discus Reeve, $H$. madaka Habe, $H$. gigantea Gmelin, $H$. diversicolor supertexta Reeve, and $H$. diversicolor diversicolor Reeve (Kim et al., 1988). However, the external morphology of these species is quite similar: natural hybrids are frequently found (Miyaki et al., 1995), and recent climate changes can result in animals shifting their distributions northward, complicating the morphological distinctiveness even further. Thus, traditional morphological characters (Ino, 1952), which are environmentally influenced, have led to conflicting species identifications. Morphological variability produced by phenotypic plasticity has been reported for gastropod shells (Wullschleger and Jokela, 2002; Smith and Ruiz, 2004).

The use of molecular markers has proved to be a useful tool for complex taxonomic identification and genetic relationship determination where morphological characteristics are ambiguous or cryptic (Miura et al., 2005; Yoon et al., 2011; An et al., 2005, 2012; Choi and Kim, 2012; Han et al., 2012; Hong et al., 2012; Lee and Hur, 2012). The random amplified polymorphic DNA-polymerase chain reaction (RAPD-PCR) technique is a relatively simple and cheap method that allows differentiation of taxa without the need to know their genomes (Williams et al., 1990). The main reason for the success of RAPD analysis is the identification of numerous genetic markers from small amounts of DNA without the need of molecular characterization of the genome of the taxa under study. Furthermore, the complete genome is screened, and genetic polymorphisms can be visualized within $24 \mathrm{~h}$ from the extraction of genomic DNA. Like other genetic markers, the RAPD technique has some limitations: limited reproducibility, dominance of markers, and limited applicability above generic level for systematic studies (Callejas and Ochando, 2001). However, among DNA fingerprinting techniques, RAPD requires the least in technology, labor, and cost (Black, 1993). RAPD markers have been used for species identification and determining genetic relationships for many other marine organisms, including abalones (Klinbunga et al., 2000; Costa et al., 2004).

Universal rice primers (URPs), which can be used in PCR fingerprinting of various organisms, including plants, animals, and microorganisms, were developed from repetitive 
sequence of rice genome (Kang et al., 2002). URP-PCR protocol employed stringent PCR with high annealing temperature throughout the thermo-cycling reaction, affording high reproducibility. URP-PCR technique is a useful tool for the characterization and grouping of most eukaryotic or prokaryotic genomes, especially at inter- and intraspecies levels (Kang et al., 2000; Jana et al., 2005).

The present study was designed to obtain species-specific RAPD molecular markers that could distinguish among the 6 Korean Pacific abalone species and determine their genetic relationships.

\section{MATERIAL AND METHODS}

\section{Sample collection and DNA extraction}

Samples of 6 Pacific abalones were collected between February and May of 1999 and again in 2000 from Jeju Island, Korea, except one species, H. discus hannai, from Pohang, Korea. Total genomic DNA was extracted from mantle musculature of the abalone samples. The removed musculatures were minced and lysed in TNES-Urea buffer ( 6 or $8 \mathrm{M}$ urea; $10 \mathrm{mM}$ Tris-HCl, $\mathrm{pH}$ $7.5 ; 125 \mathrm{mM} \mathrm{NaCl} ; 10 \mathrm{mM}$ EDTA; $1 \%$ SDS; Asahida et al., 1996). The genomic DNA was precipitated from the lysate with $100 \%$ ethanol. Following an ethanol wash, the DNA was solubilized in water (or $8 \mathrm{mM} \mathrm{NaOH}$ ). DNA was diluted with water to a final concentration of $20 \mathrm{ng} / \mu \mathrm{L}$.

\section{Primers and PCR amplification}

Primers and PCR conditions are adopted from Kang et al. (1997). Sequences of URP primers are listed in Table 1. Amplification of abalone genomic DNA using URP primers was performed in a PTC-100 thermal cycler (MJ Research, USA). PCR were conducted in 50- $\mu \mathrm{L}$ volumes. Each reaction contained $5 \mu \mathrm{L}$ 10X EX TaqTM buffer (Takara, Shiga, Japan), 0.2 $\mathrm{mM}$ each dNTP, $2 \mu \mathrm{L}$ each primer (100 ng), $2.5 \mathrm{U}$ EX TaqTM polymerase (Takara), and 5 $\mu \mathrm{L}$ genomic DNA. The temperature regime used for the amplification was 35 repetitions of a three-step cycle consisting of denaturation at $95^{\circ} \mathrm{C}$ for $1 \mathrm{~min}$, annealing at $55^{\circ} \mathrm{C}$ for $1 \mathrm{~min}$, and extension at $72^{\circ} \mathrm{C}$ for $2 \mathrm{~min}$. Denaturation for the first cycle was $4 \mathrm{~min}$ at $95^{\circ} \mathrm{C}$ and extension for the final cycle was $7 \mathrm{~min}$ at $72^{\circ} \mathrm{C}$. Next, $15 \mu \mathrm{L}$ URP-PCR products were electrophoresed on $2 \%$ agarose gel with TAE buffer. DNA fragments in the gel were visualized by staining with ethidium bromide and photographed under UV transilluminator.

The primers that produced good amplification (clearly defined bands that differentiated among the 6 abalone species) were used in the next amplification step. The primers that simultaneously showed different and consistent amplification results between species were screened. At this stage, primers were considered informative and reliable for identification and differentiation between species when they produced a species-specific amplicon in all individuals of one species.

\section{Data analysis}

The RAPD patterns of the individuals were compared between different species. URPPCR products of each abalone were scored for their presence $($ value $=1$ ) or absence (value = 
$0)$. Pairwise similarities $\left(\mathrm{S}_{\mathrm{AB}}\right)$ between individuals were calculated using the data generated from the RAPD profiles using the following formula (Nei and Li, 1979): $\mathrm{S}_{\mathrm{AB}}=2 \mathrm{~N}_{\mathrm{AB}} /\left(\mathrm{N}_{\mathrm{A}}+\right.$ $\mathrm{N}_{\mathrm{B}}$ ), where $\mathrm{N}_{\mathrm{AB}}$ is the number of fragments common between individuals $\mathrm{A}$ and $\mathrm{B}$, and $N_{\mathrm{A}}$ and $N_{\mathrm{B}}$ are the total number of fragments processed by individuals $\mathrm{A}$ and $\mathrm{B}$. On the basis of the similarity coefficient, we performed cluster analysis with the unweighted pair-group method with an arithmetic average (UPGMA) algorithm by using the statistical program NTSYSpc (version 2.01; Rohlf, 1998) to produce a dendrogram. One-way analysis of variance was applied using SAS (version 6.12, SAS Institute, 1989).

\section{RESULTS}

\section{Determination of species-specific RAPD profiles}

The RAPD-PCR technique can produce non-reproducible amplification products (Harry et al., 1998). Thus, reactions were performed following strict protocol with standardized conditions. Further, all amplification reactions were carried out, at least, 3 times in order to clearly score reproducible bands.

Twelve different URP primers possessing 50\% G + C content were screened (Table 1). They were used as template to assess the wide distribution of the URP nucleotide motif sequences in the genome of the 6 Pacific abalone species. The number of amplified bands detected varied, depending on the primers, species, and individuals. Of the 12 primers screened, 7 generated reproducible profiles (URP1F, URP2F, URP2R, URP6R, URP9F, URP13R, and URP25F). Five primers did not amplify at all or produced highly inconsistent amplification products from the same individuals and were excluded from further analysis. The representative gel pictures showing the banding patterns of RAPD profiles obtained in this analysis are shown in Figure 1. In general, the number of resolved amplified fragments varied from 4 to 13, with the size range varying from 100 to 6000 base pairs. Of the total 129 scorable bands in the 24 individuals from the 6 Pacific abalone species, 27 were species-specific bands (Figure 1). Of the 129 scorable bands, 4 were monomorphic for all 6 species. Furthermore, bands present in all specimens of 2 or more species and absent in the remaining species were detected. Such "shared-diagnostic" bands might be considered as "supragroup markers" (A, C, D, F, G, I, J, K, L, M, N, O, P, Q, R, S, U, X, Y, and AA). Species-diagnostic markers were also observed (B, E, H, $\mathrm{T}, \mathrm{V}, \mathrm{W}$, and $\mathrm{Z}$ ). These are bands present in all individuals from one species and absent from all other species. Thus, one species-diagnostic band each was found in H. madaka and H. gigantea.

\begin{tabular}{llcc}
\multicolumn{2}{l}{ Table 1. List of 12 URP primers used in PCR. } & & \\
\hline Primers & Sequences $\left(5^{\prime}-3^{\prime}\right)$ & GC content $(\%)$ & $T_{\mathrm{m}}\left({ }^{\circ} \mathrm{C}\right)$ \\
\hline URP1F & ATCCAAGGTCCGAGACAACC & 50 & 55 \\
URP2F & GTGTGCGATCAGTTGCTGGG & & \\
URP2R & CCCAGCAACTGATCGCACAC & \\
URP4R & AGGACTCGATAACAGGCTCC & \\
URP6R & GGCAAGCTGGTGGGAGGTAC & \\
URP9F & ATGTGTGCGATCAGTTGCTG & \\
URP13R & TACATCGCAAGTGACACAGG & \\
URP17R & AATGTGGGCAAGCTGGTGGT & \\
URP25F & GATGTGTTCTTGGAGCCTGT & \\
URP30F & GGACAAGAAGAGGATGTGGA & \\
URP32F & TACACGTCTCGATCTACAGG & \\
URP38F & AAGAGGCATTCTACCACCAC & \\
\hline$T_{\mathrm{m}}=$ optimal annealing temperature.
\end{tabular}




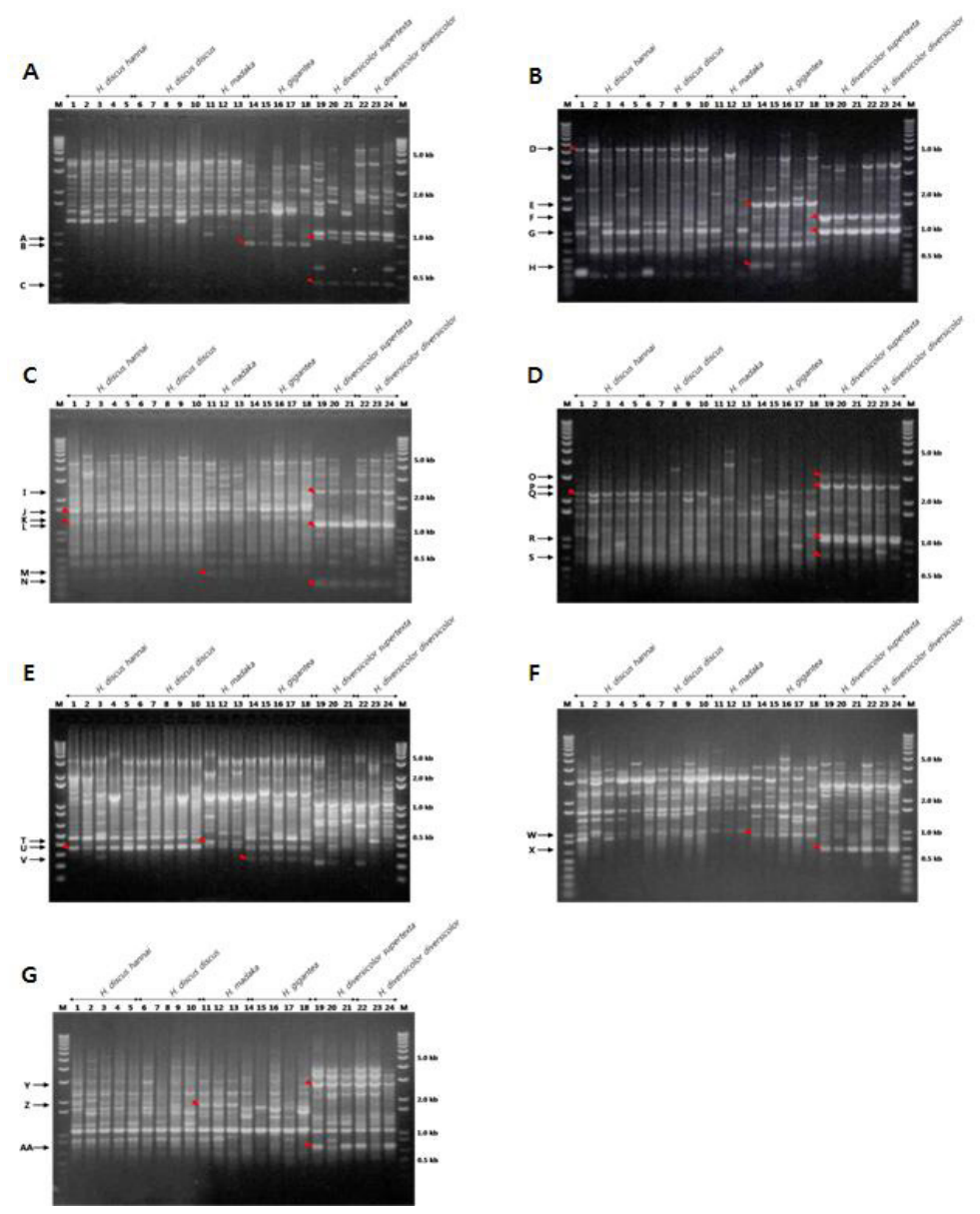

Figure 1. PCR profiles of the six Pacific abalone species generated by seven URP primers. PCR products were resolved by agarose gel $(2 \%)$ and visualized by staining with ethidium bromide. A. URP1F, B. URP2F, C. URP2R, D. URP6R, E. URP9F, F. URP13R, G. URP25F. Lane $M=1-\mathrm{kb}$ ladder (Promega, USA), lanes 1-5 = Haliotis discus hannai, lanes 6-10 $=$ H. discus discus, lanes 11-13=H. madaka, lanes 14-18=H. gigantean, lanes 19-21= $H$. diversicolor supertexta, lanes 22-24 $=H$. diversicolor diversicolor.

The presence of supragroup markers and species-diagnostic bands in the 6 Pacific abalone species generated different species-specific patterns with the 7 URP primers in this study.

\section{Interspecies genetic similarity coefficients and phylogeny}

Although there was some variation between individuals within a given species (Figure 1), most of the bands were not variable among different individuals of a given species. Intraspecies variation was detected with some of the primers screened (Figure 1); however, primer-wise level of polymorphism was low. The RAPD profile of each species was unique in terms of numbers and positions of bands. The average intra- and interspecific genetic similarity coefficients are presented in Table 2 . 
H.S. An et al.

6314
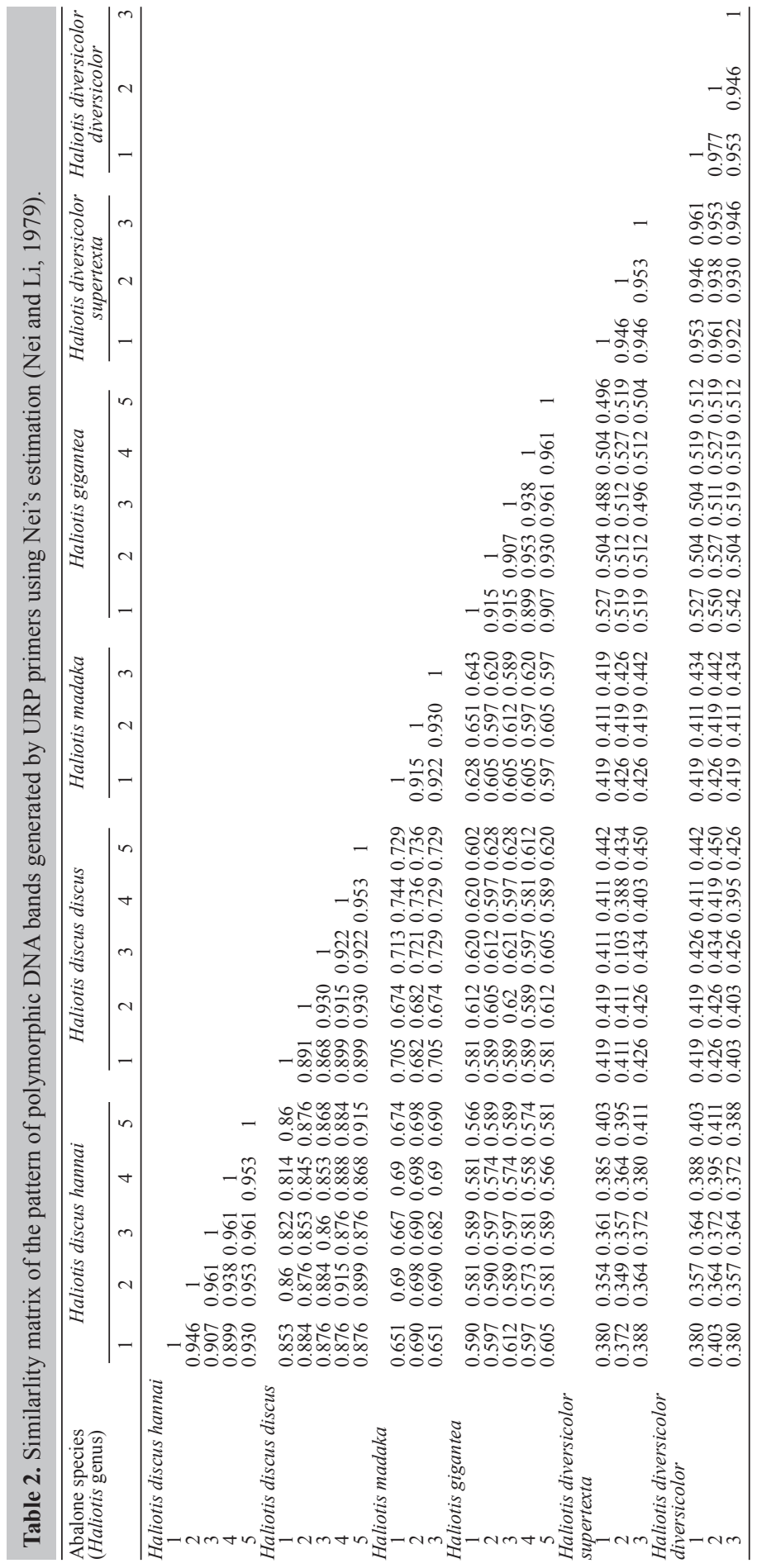

Genetics and Molecular Research 12 (4): 6309-6318 (2013)

CFUNPEC-RP www.funpecrp.com.br 
The dendrogram generated by UPGMA showed that the 6 species were divided into 2 groups at 0.44 similarity level, which were genetically distant from each other and exhibited little internal phylogenetic resolution (Figure 2). One group included $H$. discus hannai, $H$. discus discus, $H$. madaka, and $H$. gigantea, which were divided into 2 groups at 0.52 similarity level: one group contained $H$. discus hannai, $H$. discus discus, and $H$. madaka, and the other contained $H$. gigantea. $H$. diversicolor supertexta and $H$. diversicolor diversicolor belonged to the other group. H. discus hannai was the closest to $H$. discus discus with a genetic similarity of 0.870 , whereas $H$. diversicolor supertexta was the closest to $H$. diversicolor diversicolor with a genetic similarity of 0.946 . The interspecies similarity values calculated between the 6 species were tested by one-way ANOVA and found to be significantly different at $\mathrm{P}<0.05$ with one exception between $H$. diversicolor supertexta and $H$. diversicolor diversicolor.

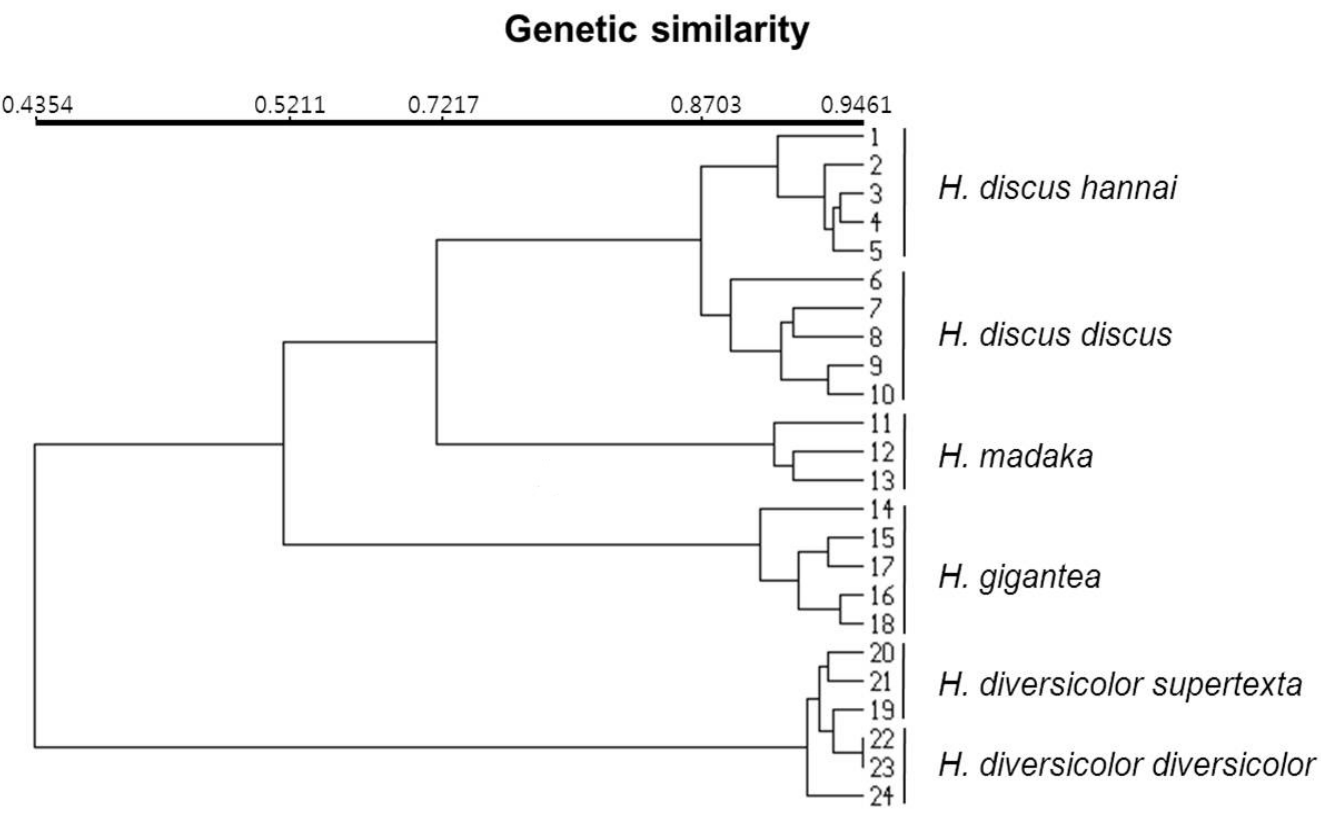

Figure 2. Phylogenetic classification of 24 Pacific abalones generated by UPGMA cluster analysis of the similarity values given in Table 2 .

\section{DISCUSSION}

Of the 129 different bands detected with the 7 URP primers, 4 monomorphic bands can be considered, on a preliminary basis, as diagnostic for the 6 eastern Pacific abalone species, because they were present in all individuals analyzed. Species-diagnostic bands were also found in $H$. madaka and $H$. gigantea. Although each primer amplified a different set of DNA fragments, all oligonucleotides failed to generate any specific diagnostic band that could lead to identification of the other 4 abalone species. Nevertheless, simultaneously many bands were produced by each primer, which by themselves or combined with other primers, identified a unique genotype in each individual analyzed.

In addition to species-diagnostic bands, the amplification of shared bands, which are 
conserved among all individuals of 2 or more species and absent in the remaining species, could be employed as diagnostic characters at higher taxonomic levels. Consequently, depending on the level of identification required, a single primer or a combination of 2 can generate clear diagnostic profiles. As the number of specific markers increases, the efficiency for unambiguous identification also increases.

The RAPD profiles generated for each species can be used for systematic inference. The 6 eastern Pacific abalone species were genetically distinct from each other and could be partitioned into at least 2 groups according to the RAPD data: one group of $H$. discus hannai, $H$. discus discus, $H$. madaka, and $H$. gigantea, and the second group of $H$. diversicolor supertexta and $H$. diversicolor diversicolor. The 2 groups are also distinguished from each other in terms of the major biological features, such as the shell shapes and number of chromosomes (Miyaki et al., 1999; Yoo, 2000). In general, the genetic divisions identified by our data correspond with those from DNA sequences as well as the taxonomic subdivisions previously proposed on the basis of morphological characters (Lee and Vacquier, 1995; An et al., 2005). Taken together, our findings suggest that the genetic relationships between $H$. discus hannai and $H$. discus discus, as well between $H$. diversicolor aquatilis and $H$. diversicolor diversicolor, are very close and may require additional analyses based on more polymorphic nuclear loci to determine whether the current species designations are accurate.

The RAPD assay has been used to construct phylogenetic trees for resolving taxonomic problems in many organisms (Guerra et al., 2010; Abdul Muneer et al., 2011; Apostolidis et al., 2011). The major limitation of the RAPD technique is repeatability. Strict adherence to protocol and standardized reactions can improve repeatability. Nevertheless, the specific characteristics of the RAPD method such as random and uncharacterized multiple genome loci, dominant nature of markers, and possibility of comigrating and nonhomologous bands limit its use in genetic studies. Obtaining systematic conclusions on the basis of RAPD analysis alone might yield inaccurate results. Despite these limitations, RAPD analysis can be used effectively for initial assessment of genetic variation among marine species, particularly in abalones, for which very little information is available (Marín et al., 2007).

The use of URP markers in the present study enabled the distinction of different species of Pacific abalones at the molecular level and classification of species-specific DNA fingerprint groups. Our study also indicates that rice repeat sequences are conserved among mollusk species such as abalones, allowing the use of the same repeat sequences as PCR primers to detect variation at species levels. To our knowledge, there are no reports on the use of repeat sequences of rice as a single primer for genetic differentiation of Pacific abalone species. Because of their potential to reveal polymorphism among the 6 Pacific abalone species, URP primers could be considered as informative because $58.3 \%$ of the URP primers worked well with the genomic DNA of Pacific abalones and produced numerous DNA bands.

In summary, the 7 URP primers produced good DNA amplification profiles and differentiated individuals at the species level. The cluster analysis classified the 6 species of Pacific abalones into 2 groups on the basis of the URP-PCR banding patterns (Figure 2). Each group revealed little internal variation, suggesting that the species within each group are very closely related. However, consistent species-specific amplicons were found among the species, indicating the value of RAPD markers for species identification. In this study, the use of URP primers as markers for fingerprinting and estimating genetic relatedness of the 6 Pacific abalone species at the DNA level provides new types of DNA markers that could be used in the fingerprinting of other mollusk genomes. 


\section{ACKNOWLEDGMENTS}

Research supported by the National Fisheries and Development Institute (NFRDI; contribution number \#RP-2013-BT-041). The views expressed herein are those of the authors and do not necessarily reflect the views of NFRDI.

\section{REFERENCES}

Abdul Muneer PM, Gopalakrishnan A, Shivanandan R, Basheer VS, et al. (2011). Genetic variation and phylogenetic relationship between two species of yellow catfish, Horabagrus brachysoma and H. nigricollaris (Teleostei: Horabagridae) based on RAPD and microsatellite markers. Mol. Biol. Rep. 38: 2225-2232.

An HS, Jee YJ, Min KS, Kim BL, et al. (2005). Phylogenetic analysis of six species of pacific abalone (Haliotidae) based on DNA sequences of 16s rRNA and cytochrome $\mathrm{c}$ oxidase subunit I mitochondrial genes. Mar. Biotechnol. 7: 373380.

An HS, Kim MJ, Lee JW and Lee WO (2012). Molecular identification of Korean catfish (Siluriformes) based on two genetic markers. Genes Genomics 34: 695-702.

Apostolidis AP, Gelia D and Mamuris Z (2011). Genetic diversity among Balkan trout populations based on RAPD analysis. Genetika 47: 1097-1102.

Asahida T, Kobayashi T, Saitoh K and Nakayama I (1996). Tissue preservation and total DNA extraction from fish stored at ambient temperature using buffers containing high concentration of urea. Fish. Sci. 62: 727-730.

Black WC (1993). PCR with arbitrary primers: approach with care. Insect Mol. Biol. 2: 1-6.

Callejas C and Ochando MD (2002). RAPD Markers as Diagnostic keys for Cyprinidae Identification: Implications for Conservation Management. In: Freshwater Fish Conservation: Options for the Future (Collares-Pereira MJ). Fishing News Books, Blackwell Science, Oxford, 322-330.

Choi CG and Kim JM (2012). Detection of Laminariaceae species based on PCR by family-specific ITS primers. Fish. Aquat. Sci. 15: 157-162.

Costa FO, Cunha MR, Neuparth T, Theodorakis CW, et al. (2004). Application of RAPD DNA fingerprinting in taxonomic identification of amphipods: a case-study with Gammarus species (Crustacea: Amphipoda). J. Mar. Biol. Assoc. U. K. 84: 171-178.

Guerra AL, Lima AV, Taddei FG and Castiglioni L (2010). Genetic polymorphism, molecular characterization and relatedness of Macrobrachium species (Palaemonidae) based on RAPD-PCR. Genet. Mol. Res. 9: 2317-2327.

Han HS, Nam BH, Kang JH, Kim YK, et al. (2012). Genetic variation in wild and cultured populations of the sea squirt Halocynthia roretzi inferred from microsatellite DNA analysis. Fish. Aquat. Sci. 15: 151-155.

Harry M, Robin S and Lachaise D (1998). L'utilisation de marqueurs génétiques polymorphes (RAPDs) en entomologie evolutive et apliquée. Ann. Soc. Entomol. Fr. 34: 9-32.

Hong SE, Kim JG, Yu JN, Kim KY, et al. (2012). Genetic variation in the Asian shore crab Hemigrapsus sanguineus in Korean coastal waters as inferred from mitochondrial DNA sequences. Fish. Aquat. Sci. 15: 49-56.

Ino T (1952). Biological studies on the propagation of Japanese abalone (genus Haliotis). Bull. Tokai Reg. Fish. Res. Lab. 5: 1-102.

Jana TK, Singh NK, Koundal KR and Sharma TR (2005). Genetic differentiation of charcoal rot pathogen, Macrophomina phaseolina, into specific groups using URP-PCR. Can. J. Microbiol. 51: 159-164.

Kang HW, Go SJ, Eun MY and Chung TY (1997). Genetic Characterization of Repetitive Sequence Derived from Korean Red Rice. Proceeding of the 8th SABRAO general congress and the Annual Meeting of the Korean, Breending Society, Seoul, 421-422.

Kang HW, Go SJ, Ryu JC, Kim KT, et al. (2000). Fingerprinting Genomes of Various Organisms Using PCR with URP Primers Developed from Repetitive Sequence of Rice. Plant and Animal Genome VIII, Conference San Diego, 190.

Kang HW, Park DS, Go SJ and Eun MY (2002). Fingerprinting of diverse genomes using PCR with universal rice primers generated from repetitive sequence of Korean weedy rice. Mol. Cell. 13: 281-287.

Kim Y, Jee YJ, Kim SH, Baik JM and Yang SG (1988). Interspecific characteristic of abalones in the southern waters of Korea. Bull. Natl. Fish. Res. Dev. Agency 42: 71-80.

Klinbunga S, Ampayup P, Tassanakajon A, Jarayabhand P, et al. (2000). Development of species-specific markers of the tropical oyster (Crassostrea belcheri) in Thailand. Mar. Biotechnol. 2: 476-484.

Lee HJ and Hur SB (2012). Comparison between phylogenetic relationships based on 18S rDNA sequences and growth by salinity of Chlorella-like species (Chlorophyta). Fish. Aquat. Sci. 15: 125-135. 
Lee YH and Vacquier VD (1995). Evolution and systematics in Haliotidae (Mollusca: Gastropoda): inferences from DNA sequences of sperm lysin. Mar. Biol. 124: 267-278.

Marín SA, Haye PA, Marchant S and Winkler FM (2007). Molecular markers used to analyze species-specific status in abalones with ambiguous morphology. J. Shellfish Res. 26: 833-837.

Miura O, Kuris AM, Torchin ME, Hechinger RF, et al. (2005). Molecular-genetic analyses reveal cryptic species of trematodes in the intertidal gastropod, Batillaria cumingi (Crosse). Int. J. Parasitol. 35: 793-801.

Miyaki K, Niiyama H, Kiyomoto S and Tanabe O (1995). Occurrence of a possible abalone hybrid in Tsushima Island, northern Kyushu. Nagasakiseibuthugakaishi 45: 19-22.

Miyaki K, Matsuda M and Tabeta O (1999). Karyotype of the giant abalone, Nordotis madaka. Fish. Sci. 65: 317-318.

Nei M and Li WH (1979). Mathematical model for studying genetic variation in terms of restriction endonucleases. Proc. Natl. Acad. Sci. U. S. A. 76: 5269-5273.

Rohlf FJ (1998). NTSYS-pc Numerical Taxonomy and Multivariate Analysis System. Version 2.01. Exeter Software, Setauket.

SAS Institute (1989). SAS/STAT User's Guide, Version 6, 4th. SAS Institute, Cary, 1-943.

Smith NF and Ruiz GM (2004). Phenotypic plasticity in the life history of the mangrove snail Cerithidea scalariformis. Mar. Ecol. Prog. Ser. 284: 195-209.

Williams JG, Kubelik AR, Livak KJ, Rafalski JA, et al. (1990). DNA polymorphisms amplified by arbitrary primers are useful as genetic markers. Nucleic Acids Res. 18: 6531-6535.

Wullschleger EB and Jokela J (2002). Morphological plasticity and divergence in life-history traits between two closely related freshwater snails, Lymnaea ovata and Lymnaea peregra. J. Mollus. Stud. 68: 1-5.

Yoo SK (2000). Cheonhaeyangsik (Shallow-Sea Aquaculture). Gudeok Press, Busan, 289.

Yoon M, Jung JY, Nam YK and Kim DS (2011). Genetic diversity of thread-sail filefish Stephanolepis cirrhifer populations in Korean coastal waters inferred from mitochondrial DNA sequence analysis. Fish. Aquat. Sci. 14: 16-21.

Zhang G, Wang Z, Chang Y, Song J, et al. (1998). Triploid induction in pacific abalone Haliotis discus hannai Ino by 6-dimethylaminopurine and the performance of triploid juveniles. J. Shellfish Res. 17: 783-788. 